\title{
Therapeutics targeting CD90-integrin-AMPK-CD133 signal axis in liver cancer
}

\author{
Wei-Ching Chen ${ }^{1,2}$, Yung-Sheng Chang ${ }^{1,2}$, Hui-Ping Hsu ${ }^{3}$, Meng-Chi Yen ${ }^{1}$, Hau-Lun \\ Huang $^{1,2}$, Chien-Yu Cho ${ }^{1,2}$, Chih-Yang Wang ${ }^{1,2}$, Tzu-Yang Weng ${ }^{1,2}$, Po-Ting Lai ${ }^{4}$, \\ Ching-Shih Chen ${ }^{4}$, Yih-Jyh Lin ${ }^{3}$, Ming-Derg Lai ${ }^{1,2,5}$ \\ ${ }^{1}$ Department of Biochemistry and Molecular Biology, College of Medicine, National Cheng Kung University, Tainan, Taiwan \\ ${ }^{2}$ Institute of Basic Medical Sciences, College of Medicine, National Cheng Kung University, Tainan, Taiwan \\ ${ }^{3}$ Department of Surgery, College of Medicine, National Cheng Kung University, Tainan, Taiwan \\ ${ }^{4}$ Division of Medicinal Chemistry, College of Pharmacy, The Ohio State University, Columbus, OH, USA \\ ${ }^{5}$ Center for Infectious Diseases and Signaling Research, College of Medicine, National Cheng Kung University, Tainan, Taiwan \\ Correspondence to: \\ Ming-Derg Lai, e-mail: a1211207@mail.ncku.edu.tw \\ Yih-Jyh Lin, e-mail: lyj007@mail.ncku.edu.tw \\ Keywords: cancer stem cell marker, integrin, AMPK, mTOR, OSU-CG5 \\ Abbreviations: HCC, hepatocellular carcinoma; HGF, hepatocyte growth factor; TGF- $\beta-1$, transforming growth factor- $\beta-1$; CSC, \\ cancer stem cell \\ Received: June 09, $2015 \quad$ Accepted: October 12, $2015 \quad$ Published: October 22, 2015
}

\section{ABSTRACT}

CD90 is used as a marker for cancer stem cell in liver cancer. We aimed to study the mechanism by which CD90 promoted liver cancer progression and identify the new therapeutic targets on CD90 signal pathway. Ectopic expression of CD90 in liver cancer cell lines enhanced anchorage-independent growth and tumor progression. Furthermore, CD90 promoted sphere formation in vitro and upregulated the expression of the cancer stem cell marker CD133. The CD133 expression was higher in CD45-CD90+ cells in liver cancer specimen. The natural carcinogenic molecules TGF- $\beta-1$, HGF, and hepatitis B surface antigen increased the expression of CD90 and CD133. Inhibition of CD90 by either shRNA or antibody attenuated the induction of CD133 and anchorage-independent growth. Lentiviral delivery of CD133 shRNA abolished the tumorigenicity induced by CD90. Ectopic expression of CD90 induced mTOR phosphorylation and AMPK dephosphorylation. Mutation of integrin bindingRLD domain in CD90 attenuated the induction of CD133 and anchorage-independent growth. Similar results were observed after silencing $\beta 3$ integrin. Signaling analyses revealed that $A M P K / m T O R$ and $\beta 3$ integrin were required for the induction of CD133 and tumor formation by CD90. Importantly, the energy restriction mimetic agent OSUCG5 reduced the CD90 population in fresh liver tumor sample and repressed the tumor growth. In contrast, sorafenib did not decrease the CD90+ population. In conclusion, the signal axis of CD90-integrin-mTOR/AMPK-CD133 is critical for promoting liver carcinogenesis. Molecules inhibiting the signal axis, including OSU-CG5 and other inhibitors, may serve as potential novel cancer therapeutic targets in liver cancer.

\section{INTRODUCTION}

Liver cancer is a common cause of cancer-related deaths around the world and is a result of the accumulation of genetic and epigenetic alterations. There are several etiological factors and potent stimulators involved in liver cancer progression, such as hepatitis B virus
(HBV), transforming growth factor- $\beta-1$ (TGF- $\beta-1)$, and hepatocyte growth factor (HGF). The upregulation of TGF- $\beta-1$ in hepatocellular carcinoma (HCC) correlates with hepatic carcinogenesis and tumor progression [1]. The serum levels of HGF are elevated in a variety of liver diseases [2], and HGF concentrations are used as a tumor marker for HCC [3]. In addition, the hepatitis B virus 
surface antigen is shown to promote tumor formation [4]. A mutated HBV large surface protein with a deletion in the antigen region has been found in the serum of patients with HBV infection, and this protein enhances anchorage-independent growth [5]. The etiologic agents have been proposed to induce tumor progression through the hierarchy model or the stochastic model (these models are not mutually exclusive). In the stochastic model, the instigating cells acquire a proliferative advantage over the surrounding cells through the accumulation of multiple genetic and epigenetic alterations, as demonstrated in the development of colon cancer [6]. Alternatively, tumors may develop according to the hierarchical model, which proposes that a small population of cells within each tumor has the ability to generate a tumor and recapitulate the traits of a whole tumor [7]. These tumor-initiating cells are called cancer stem cells (CSCs). CSCs generate tumors through the stem cell processes of self-renewal and differentiation into multiple cell types; this hypothesis has been supported by studies in which a small population of leukemia cells had the ability to recapitulate the whole tumor [8].

To identify cancer-initiating cells, scientists generally separate the tumor cells into various subpopulations using cell surface markers and examine their tumor-forming ability in immunocompromised mice $[9,10]$. Several representative cell surface markers have been identified from human hepatocarcinoma cell lines and primary tissues $[11,12]$. These hepatocarcinoma CSC markers include CD133, CD90, CD44, CD24, EpCAM, and OV6. CD133, also called prominin 1 , is a 5 -transmembrane protein and a marker of normal hematopoietic stem cells. Injection of as few as 100 CD133+ brain tumor cells was found to form tumors in xenotransplantation assays, whereas the same number of CD133- cells was unable to generate tumors [13]. In addition to brain cancer, CD133 was later used to purify CSCs from several other tumor types $[14,15]$. Expression of CD133 enhances malignancy by matrix metalloproteinase (MMP)-2 and a disintegrin and metalloproteinase (ADAM) 9. CD133 increases the colony-formation ability and alters the cell cycle in HCC [16]. The increased CD133 expression correlates with poor prognosis in HCC [17]. CD133-positive HCC cells possess a greater ability to grow in soft agar and to form tumors in vivo than the corresponding CD133negative cells $[18,19]$. The expression of CD133 is regulated by DNA methylation. TGF- $\beta-1$ induces CD133 expression through the inhibition of DNMT1 and DNMT3 $\beta$, and this inhibition is partially dependent on the SMAD pathway [20]. Yang et al. identify CSCs from HCC cell lines and primary HCC tissues that are defined by the expression of the hepatic progenitor marker OV6 and activation of $\mathrm{Wnt} / \beta$-catenin signaling [21]. Gene expression and signaling pathway analyses on HCC specimens reveal that cells positive for the surface hepatic stem cell marker EpCAM have features of cancer stem cells [22]. Because some CD133+ cells are representative of $\mathrm{CSCs}$, further identification and characterization reveal that CSCs could be better defined by co-expression of CD133 and CD44 on the cell surface [23]. In contrast, the number of cells expressing CD90 (Thy1), a glycosylphosphatidylinositol (GPI)-anchored glycoprotein, is correlated with the tumorigenicity of HCC cell lines. The CD90+CD44+ cells possess a more aggressive and metastatic phenotype than the CD90+CD44- cells [24]. The function of CD90 may be dependent on cell type; activation of CD90 induces the activation and translocation of FasL via the src family kinases in lung myofibroblasts [25]. A decrease in CD90 expression has been observed in nasopharyngeal cell lines and in $65 \%$ of tumor samples. Restoration of CD90 expression causes a decrease in colony formation [26]. CD90 has an RGD-like sequence, RLD, and it binds to $\alpha v \beta 3$ integrin through its RLD sequence, thereby activating the interaction between melanoma cells and activated endothelial cells [27-29]. The binding of CD90 to $\alpha v \beta 5$ integrin is RLD-dependent because the mutated form, CD90-RLE, loses the ability to bind to the integrin on lung fibroblasts. Furthermore, the liver cancer stem cells have been classified as two groups with EpCAM or CD90 [30].

Targeted therapy is one type of cancer treatment that uses drugs to more precisely attack cancer cells. The drug development for targeted therapy is usually based on the specific mutation or dysregulated signaling pathway in cancer. Several signaling pathways, including the MAPK/ERK, PI3K/AKT/mTOR, STAT3, VEGFR and PDGFR pathway, are demonstrated to promote cancer progression $[31,32]$. Sorafenib inactivates ERK and mTOR signaling pathway and suppresses the tumor formation [33]. The combination of sorafenib and PKI-587 drives the inhibition of proliferation in liver cancer [34]. Recently, studies have indicated that cancerinitiating cells may benefit from the abundant expression of CD44 [35]. Cancer stem cell marker is not only used to define specific populations of cancer cells, but also correlates with tumor growth. Therefore, we aimed to study whether CD90 CSC marker and its downstream signaling pathway play an important role in tumor growth. In this report, we demonstrate that abundantly expressed CD90 increases sphere formation, soft agar growth, and tumorigenicity in HepG2 and Hep3B cells. In addition, CD90 enhances the expression of CD133 via the AMPK and mTOR pathways. The binding of CD90 to integrin through the RLD residues is essential for the induction of CD133 and soft agar growth. The reduction in CD133 expression attenuates the induction of soft agar growth by CD90. Our results demonstrate that the CD90-integrinAMPK-CD133 signal axis is essential for the growth of liver cancer. Therapeutics targeting the signal axis may be useful for liver cancer treatment. 


\section{RESULTS}

\section{CD90 promotes tumorigenicity in HepG2, Hep3B and $\mathrm{HuH7}$ cells}

To determine whether the CD90 cancer stem cell marker is involved in the tumorigenesis of liver cancer cell, HepG2, Hep3B and HuH7 cells were transfected with a plasmid encoding CD90. Ectopic expression of CD90 mRNA was detected by RT-PCR analysis, and surface expression of CD90 was verified by flow cytometry analysis (Figure 1A and 1B, Supplementary Figure $\mathrm{S} 1 \mathrm{~A}$ and $\mathrm{S} 1 \mathrm{~B})$. Ectopic expression of CD90 increased anchorage-independent growth in vitro and tumor formation in vivo (Figure 1C and 1D, Supplementary Figure S1C and S1D). Furthermore, the expression of CD90 in the stable transfectants was comparable to the expression of CD90 in the liver tumor samples, suggesting that the phenotype was not due to artificial overexpression in cell lines (Figure 1E).

\section{CD90 increases sphere-forming ability and the expression of stem cell marker CD133}

Ectopic expression of CD90 enhanced sphere formation in ultra-low attachment culture dishes, a capability that is one of the characteristics of cancer stem cells (Figure 2A). The expression of CD133 was dramatically enhanced by the ectopic expression of CD90 (Figure 2B). The expression of other stem cell markers, including CD44, EpCAM, and CD13, was not statistically different between the HepG2 CD90 transfectants and the parental cells (Figure 2B). In contrast, the expression of $\mathrm{CD} 24$ was higher in the CD90 transfectants (Figure 2B). The elevated expression of CD133 was further confirmed by western blotting (Figure 2C). Taken together, the results indicate that the expression of CD133 and CD24 are induced by the ectopic expression of CD90. CD133 is a CSC marker in many types of cancer, implicating its significance of cancer development. To confirm the upregulation of CD133 in vivo, we analyzed the expression of CD133 in tumor cells from clinical HCC samples. The CD45- population was used to exclude the effects from CD45+ cells. The expression of CD133 in the CD45-CD90+ tumor cells was higher than that in the CD45-CD90- tumor cells isolated from clinical HCC specimens (Figure 2D).

\section{Inactivation of CD90 by either ShRNA or antibody inhibits anchorage-independent growth and CD133 expression which are upregulated by environmental stimuli}

HGF and TGF- $\beta-1$ promotes liver cancer progression, and the serum levels of HGF and TGF- $\beta-1$ are elevated in hepatic carcinogenesis [1-3]. HGF and
TGF- $\beta-1$ induced the expression of CD133 in HepG2 and Hep3B cells, and the expression of CD133 was significantly reduced by the introduction of CD 90 shRNA (Figure 3A and 3B). The knockdown efficacy induced by CD90 shRNA in HepG2 and Hep3B cell was analyzed using quantitative RT-PCR (Figure 3C). Our previous report has indicated that HBV pre-S2 large surface protein induces a variety of pathologic conditions in the hepatocarcinoma HuH7 cell [5]. The pre-S2 mutant gene with a deletion of pre-S2 region of large surface protein ( $\triangle \mathrm{S} 2-\mathrm{LHBs})$ contains a deletion at nucleotides 4-57. $\Delta \mathrm{S} 2$-LHBs is clustered in the hepatocyte with hepatitis $\mathrm{B}$ virus infection and involved in the tumorigenesis. The expression of $\mathrm{CD} 133$ and $\mathrm{CD} 90$ in $\mathrm{HuH} 7$ transfectants expressing wild-type LHBs and $\triangle \mathrm{S} 2$-LHBs was analyzed by quantitative RT-PCR (Figure 3D and 3E). Furthermore, the induction of CD133 by the expression of the HBV large surface protein was attenuated by CD90 shRNA (Figure $3 \mathrm{~F}$ and $3 \mathrm{G}$ ). Finally, anchorage-independent growth of HBV-preS2 cells was abolished by shRNA or antibody against CD90 (Figure 3H). To further confirm the effect of CD90 shRNA in liver cancer, the lentiviral particles containing CD90 shRNA was delivered to liver cancer PLC/PRF/5 cells. The CD133 expression and anchorage-independent growth in the PLC/PRF/5 cell were attenuated by CD90 shRNA (Supplementary Figure S2A and S2B). Taken together, the results indicate that CD90 is essential for the induction of CD133 by physiological stimuli (HGF and TGF- $\beta-1$ ) or pathological alteration (the HBV large surface protein).

\section{Inhibition of CD133 abolishes the tumor growth induced by CD90}

Since overexpression of CD90 induced the expression of CD133 and anchorage-independent growth, we investigated whether CD133 was essential for the anchorage-independent growth induced by CD90. Lentiviral introduction of CD133 shRNA was used to inhibit CD133 expression (Figure 4A). Two different CD133 shRNAs significantly suppressed the anchorageindependent growth induced by $\mathrm{CD} 90$ in $\mathrm{HepG} 2$ and Hep3B CD90 transfectants (Figure 4B). Treatment with a monoclonal anti-CD133 antibody (AC133) also blocked the anchorage-independent growth induced by CD90 in hepatocellular carcinoma cells (Figure 4C), excluding the off-target effects of CD133 shRNA in general. Finally, lentiviral introduction of shCD133 in vivo inhibited tumor growth (Figure 4D). Thus, CD133 is required for the CD90-induced tumor progression.

\section{CD90-AMPK/mTOR-CD133 signaling axis functions as therapeutic target}

The mTOR and AMPK pathways are involved in the maintenance of cancer stem cells [37]; thus, we 
A
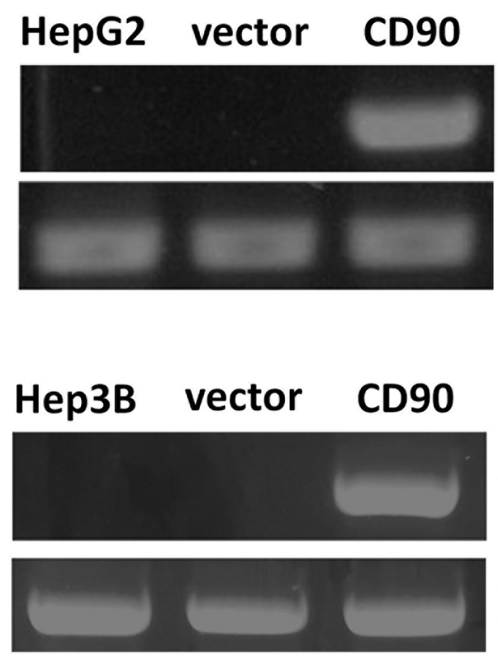

C
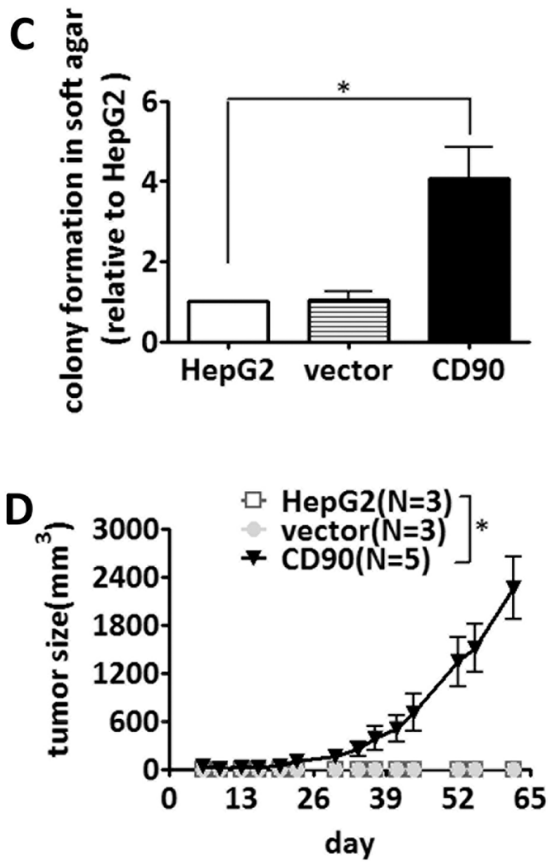

E

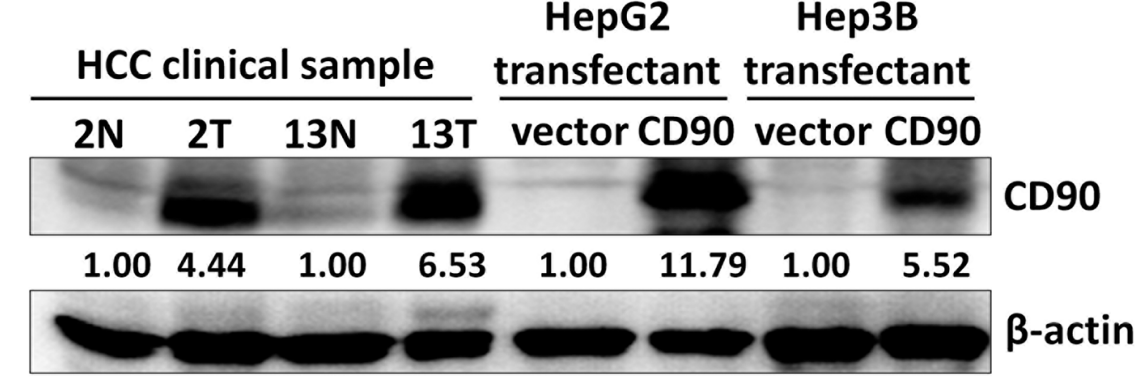

Figure 1: CD90 promotes tumor formation in liver cancer cells. CD90 mRNA expression and cell surface expression in the exogenous CD90-overexpressing stable transfectants were determined by RT-PCR A. and FACS analyses B. C. The transfectants were plated in soft agar, and the colonies were monitored for 14 days. The colonies were quantified using Image-Pro Plus software. Data represent mean \pm SEM $(n=3)$. $P$ value was calculated using one-way anova analysis and $*$ indicated $P<0.01$. D. The transfected cells were injected subcutaneously into NOD/SCID mice, and tumor growth curves were determined. Data represent mean $\pm \mathrm{SEM} . P$ value was calculated using two-way anova analysis and * indicated $P<0.0001$. E. The protein expression of CD90 in the transfectants and two pairs of tumor samples was analyzed by western blotting with an anti-CD90 antibody. 
A
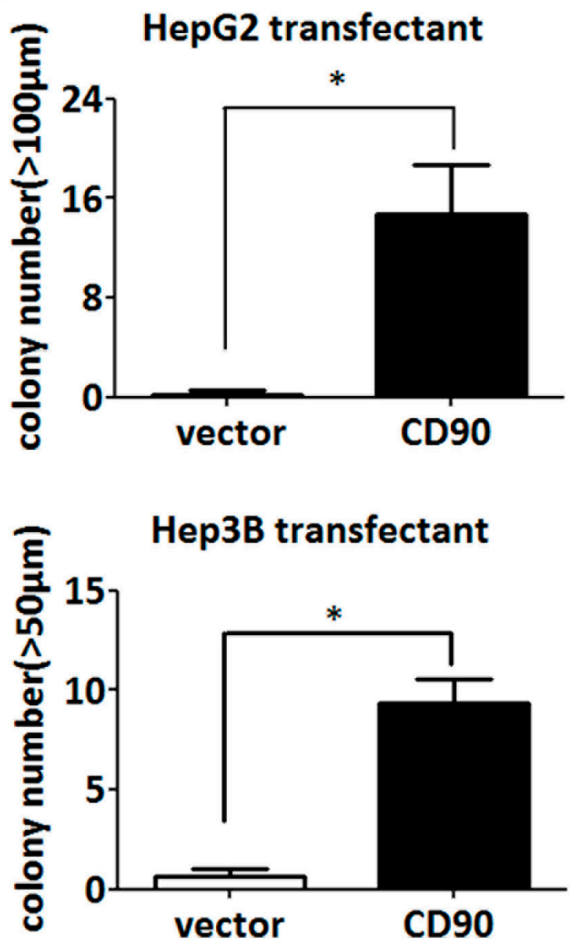

B
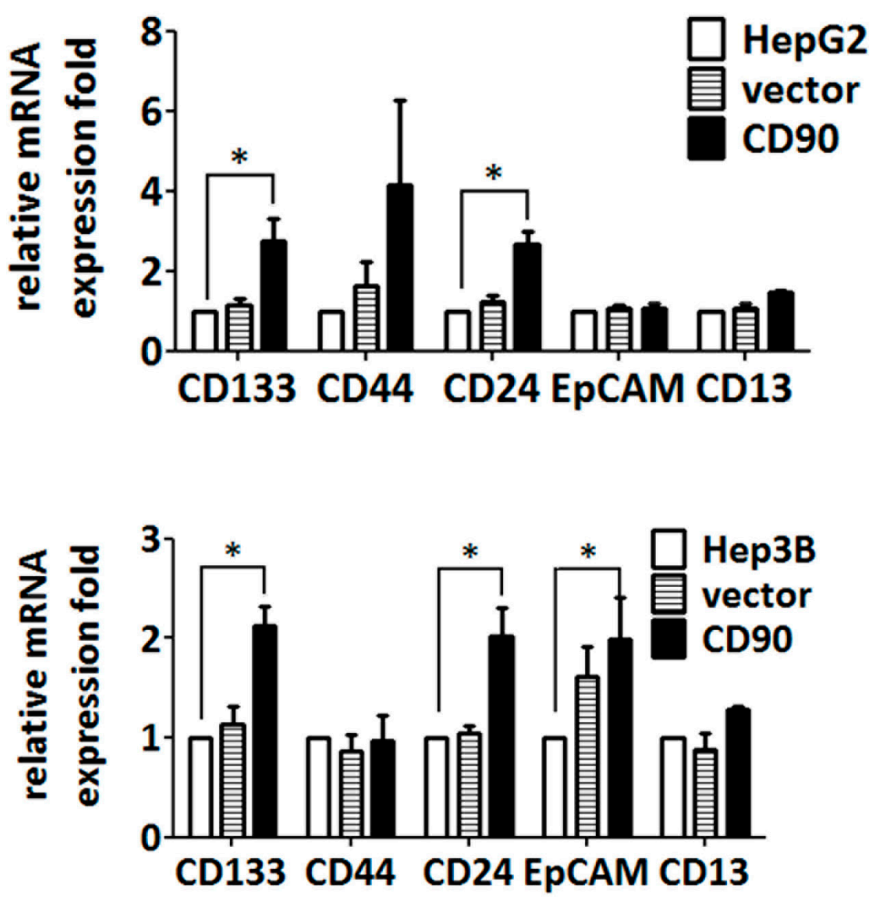

C
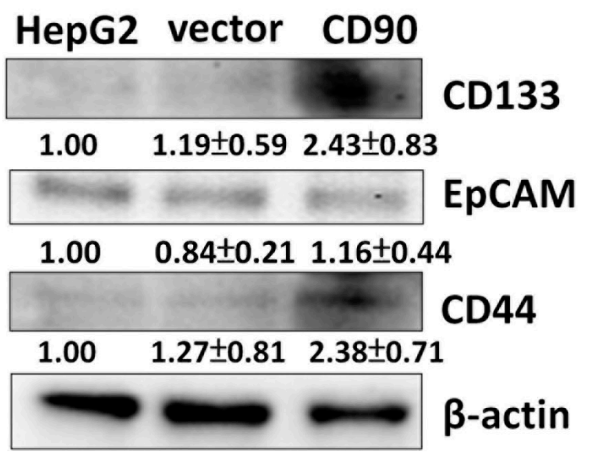

HepG2 vector CD90

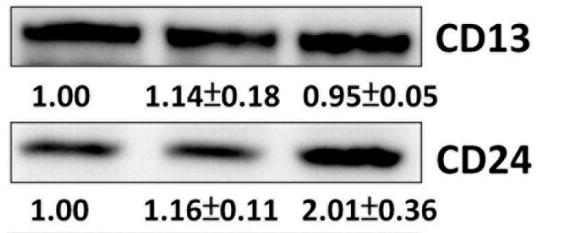

$\beta$-actin
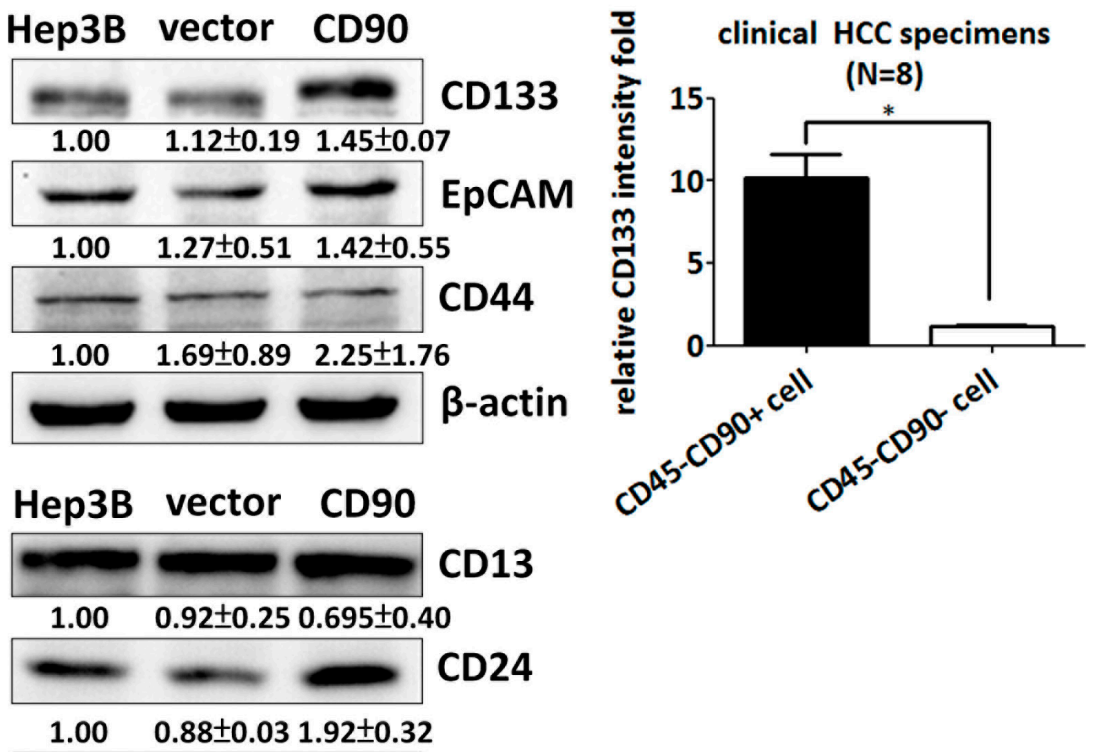

Figure 2: CD90 increases sphere formation and the expression of cancer stem cell markers in cell lines and tumor specimens. A. The transfectants were seeded into ultra-low attachment plates, and the numbers of formed spheres were counted. Data represent mean $\pm \operatorname{SEM}(n=4) . P$ value was calculated using unpaired $t$-test and $*$ indicated $P<0.01$. B. The expression of the liver cancer stem cell markers CD133, CD44, CD24, EpCAM, and CD13 was determined by quantitative RT-PCR in CD90 transfectants, control transfectants, and parental cells. The mRNA levels were normalized to HPRT. Data represent mean \pm SEM $(n=3)$. $P$ value was calculated using one-way anova analysis and * indicated $P<0.05$. C. The expression of CD133, CD44, EpCAM, CD24, and CD13 in the transfectants was determined by western blotting. The quantitative data represent mean $\pm \mathrm{SD}(n=3)$. D. The CD133 expression of the CD45-CD90+ and CD45-CD90- populations in freshly isolated HCC specimens was determined by flow cytometry. The quantitative data represent mean \pm $\operatorname{SEM}(n=8)$. $P$ value was calculated using unpaired $t$-test analysis and $*$ indicated $P<0.0001$. 

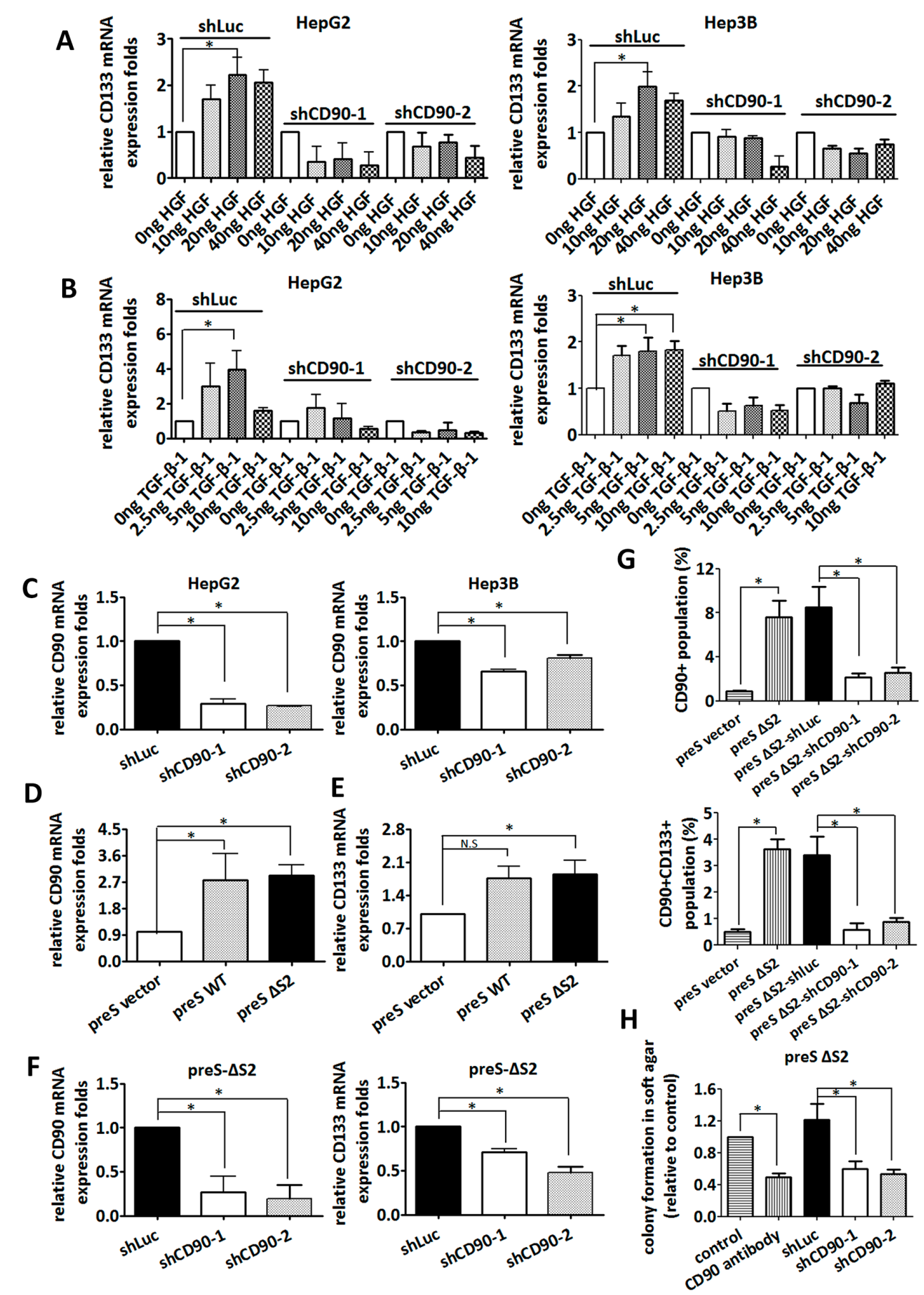

Figure 3: Silencing of CD90 inhibits anchorage-independent growth and CD133 expression induced by environmental stimuli including HGF, TGF- $\boldsymbol{\beta}-1$, or HBV large surface protein. HepG2 and Hep3B cells were infected with lentiviral particles containing shCD90 or shLuc. The infected HepG2 and Hep3B cells were then treated with HGF A. and TGF- $\beta-1$ B. at the indicated doses for 24 hours. CD133 mRNA levels were then determined by quantitative RT-PCR. C. The downregulation of CD90 mRNA was determined by quantitative RT-PCR. Data represent mean $\pm \operatorname{SEM}(n=3)$. D. The expression of CD90 in liver cancer HuH7 cells expressing the PreS2 deletion (PreS- $\Delta$ S2) mutant HBV large surface protein was examined by quantitative RT-PCR. Data represent mean $\pm \operatorname{SEM}(n=4)$. E. The expression of CD133 in liver cancer HuH7 cells expressing the PreS2 deletion (PreS- $\Delta$ S2)) mutant HBV large surface protein was examined by quantitative RT-PCR. Data represent mean $\pm \operatorname{SEM}(n=5)$. F. After infection with lentiviral particles containing shCD 90 and shLuc, total mRNA from the PreS- $\Delta$ S2 transfectants was extracted, and the expression of CD 90 and CD133 was examined by quantitative RT-PCR. Data represent mean \pm SEM $(n=4)$. G. After infection with lentiviral particles containing shCD90 and shLuc, the surface CD90 and CD133 in liver cancer HuH7 cells expressing the PreS2 deletion (PreS- $\Delta$ S2) mutant HBV large surface protein was examined by flow cytometry. Data represent mean \pm SEM $(n=4)$. H. Anchorage-independent growth was determined using soft agar assay after lentiviral infection of the indicated shRNA or CD90 antibody treatment. Data represent mean $\pm \operatorname{SEM}(n=3)$. All $P$ value was calculated using one-way anova analysis and * indicated $P<0.05$. 
A

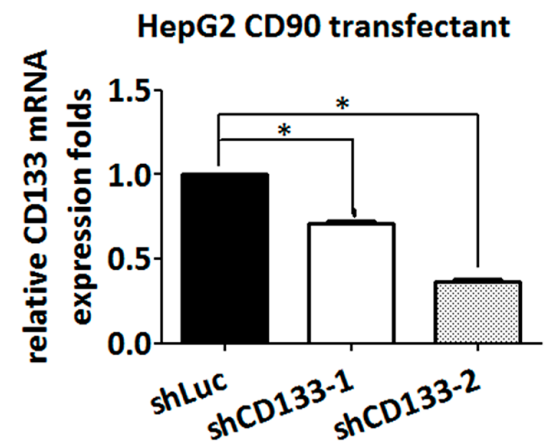

B

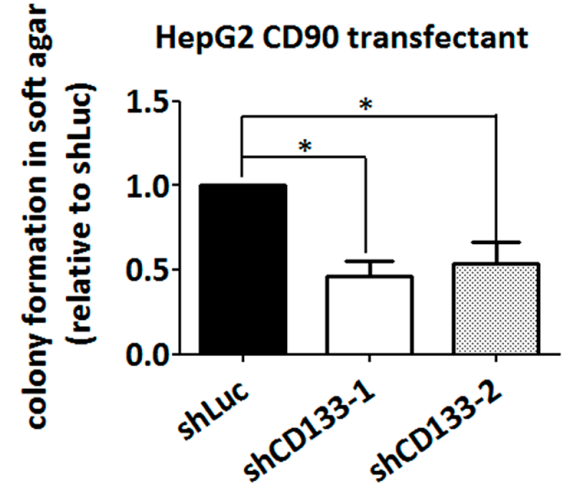

C

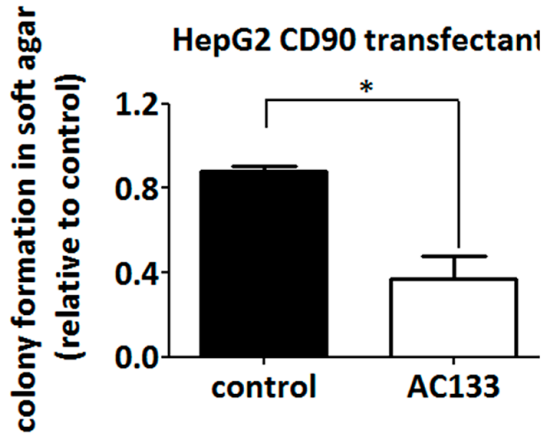

D

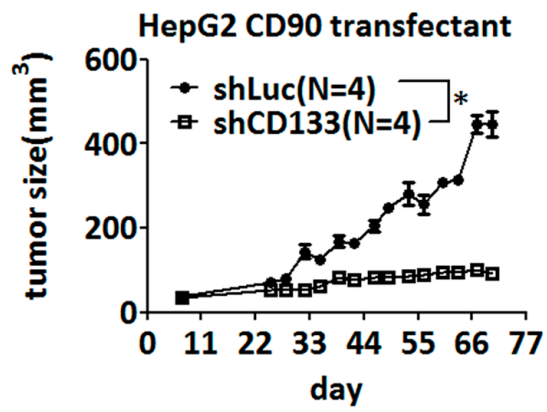

Hep3B CD90 transfectant
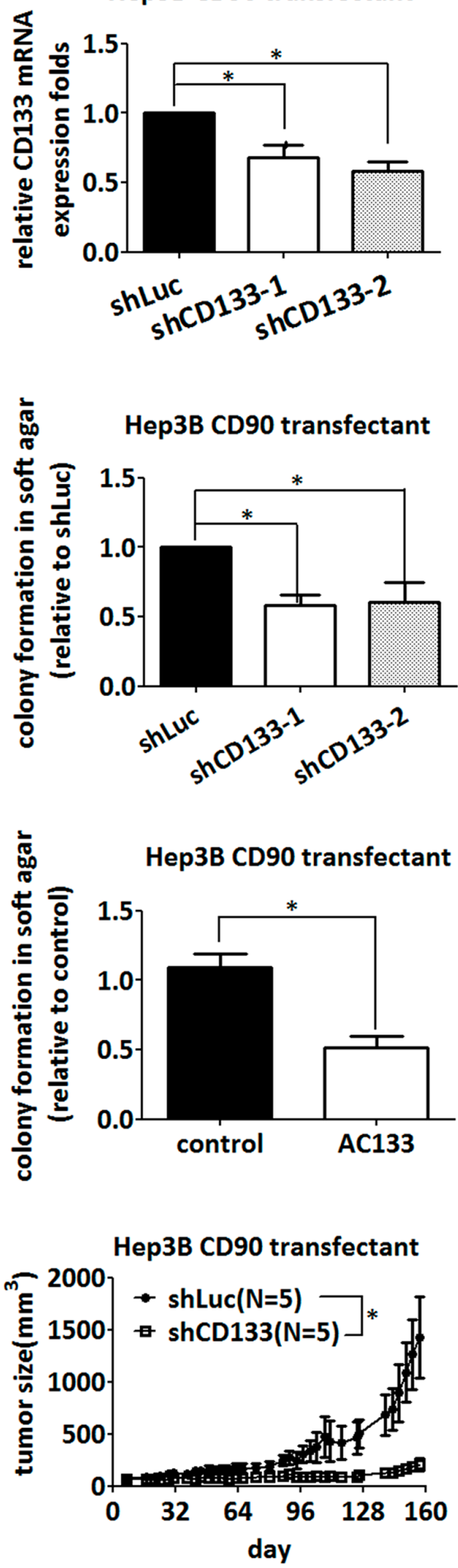

Figure 4: Inhibition of CD133 attenuates the anchorage-independent growth induced by CD90. A. CD90 transfectants were infected with two different shRNAs targeting CD133, and the downregulation of CD133 mRNA was determined by quantitative RT-PCR. Data represent mean \pm SEM $(n=4)$. B. CD90-transfected HepG2 and Hep3B cells were infected with two different shRNAs targeting CD133, and the anchorage-independent growth was determined in soft agar. Data represent mean \pm SEM $(n=4) . P$ value was calculated using one-way anova analysis and $*$ indicated $P<0.05$. C. CD90-transfected HepG2 and Hep3B cells were seeded in soft agar and incubated with the anti-CD133 antibody (AC133). Colonies were counted after 14 days. Data represent mean $\pm \operatorname{SEM}(n=3)$. $P$ value was calculated using unpaired $t$-test analysis and $*$ indicated $P<0.05$. D. CD90 transfectants were subcutaneously co-injected with lentiviral particles containing luciferase or CD133 shRNA into NOD/SCID mice. The size of tumor was measured twice a week. $P$ value was calculated using two-way anova analysis and * indicated $P<0.05$. 
investigated whether the mTOR and AMPK pathways contributes to the expression of CD133 induced by ectopic expression of CD90. HepG2 and Hep3B CD90 transfectants had higher levels of mTOR phosphorylation and lower levels of AMPK phosphorylation than the parental cells or control transfectants (Figure 5A). In contrast, the PLC/PRF/5 cells infected with lentiviral particles containing CD90 shRNA had lower levels of mTOR phosphorylation and higher levels of AMPK phosphorylation (Supplementary Figure S2C). To further determine whether mTOR and AMPK were essential for the upregulation of CD133 by CD90, we determined the effects of rapamycin (an mTOR inhibitor) and AICAR (an AMPK activator) on the expression of CD133 in the CD90 transfectants. CD133 mRNA and protein upregulation were attenuated upon rapamycin or AICAR treatment in HepG2 and Hep3B CD90 transfectants (Figure 5B and $5 \mathrm{C}$ ). Furthermore, the increase of the anchorageindependent growth in CD90 transfectants was restored by rapamycin or AICAR (Figure 5D). An energy restriction mimetic agent OSU-CG5 has been demonstrated to inhibit mTOR pathway $[38,39]$. We therefore examined the effect of OSU-CG5 on the CD90-induced anchorageindependent growth. The OSU-CG5 selectively inhibited the growth and the mTOR phosphorylation of HepG2 CD90 transfectants and Hep3B CD90 transfectants (Supplementary Figure S3A). OSU-CG5 had a comparable killing effect with sorafenib on the parental HepG2 and Hep3B cells (Supplementary Figure S3B), and selectively reduced CD90 population in Hep3B cells (Supplementary Figure S3C). Importantly, OSU-CG5 alone significantly abolished tumor growth in animal tumor model, but did not grossly decrease the weight for mice, an indication for health condition (Figure 5E and Supplementary Figure S3D). Finally, we determined whether OSU-CG5 can specifically eradicate the CD90-positive population in clinical tumor samples. OSU-CG5 had the killing effect on tumor cells and decreased the CD90-positive population in the fresh liver tumors (Figure $5 \mathrm{~F}$ and $5 \mathrm{G}$ ). In contrast, sorafenib, an inhibitor mainly works on ERK pathway [40], did not suppress the CD90-positive population cells (Figure 5G). Compared to the sorafenib, OSU-CG5 significantly inhibited the CD45-CD90+ populations from clinical tumor samples (Figure 5H). Altogether, the CD90-AMPK/mTOR-CD133 signal axis is required for hepatocarcinogenesis. OSU-CG5 was able to decrease the CD45-CD90+ tumor cells, which were potentially a population of liver cancer stem cells.

\section{The CD90 RLD domain affects anchorage- independent growth and CD133 expression}

CD90 has been shown to promote lung fibroblast differentiation through an interaction with integrin through its RLD sequence [41]. We sought to determine whether the RLD domain of CD90 is essential for the signal transduction in regulating CD133 expression. The RLD residue of CD90 was replaced with RLE, and the mutant CD90 was transfected into HepG2 and Hep3B cells. Neither anchorage-independent growth nor CD133 mRNA expression was induced by the CD90 RLE mutant (Supplementary Figure S4A and S4B). The alteration on AMPK phosphorylation and mTOR phosphorylation was attenuated in the cell lines expressing CD90 RLE mutant (Supplementary Figure S4C).

\section{Silencing of $\beta 3$ Integrin decreases tumor formation and CD133 expression}

Integrins recognize arginine-glycin-aspartic acid (RGD) sequence and contribute to the cancer cell growth. The RGD-like sequence, RLD, also binds to integrin and participates in the signaling transduction. We sought to identify the effect of integrin family in CD90 transfectant. The lentiviral particles containing $\alpha \mathrm{V}, \beta 1$, and $\beta 5$ integrin shRNA was delivered into CD90 transfectant, respectively. The integrin shRNA-induced knockdown efficacy in HepG2 and Hep3B CD90 transfectant was analyzed by quantitative RT-PCR (Supplementary Figure S5A). The CD133 expression and anchorage-independent growth ability were not consistently inhibited by $\alpha \mathrm{V}, \beta 1$, and $\beta 5$ integrin shRNA (Supplementary Figure S5B and S5C). Given the effects of RLD domain of CD90 in CD133 expression and the colocalization of CD90 and $\beta 3$ integrin [42], we next determined whether $\beta 3$ integrin contributes to the CD90-induced phenotype in HepG2 and Hep3B cells. We delivered CD90 transfectants with integrin shRNA to silence $\beta 3$ integrin (Figure 6A), and determined the expression level of CD133 and anchorageindependent growth. The expression of CD133 was reduced by $\beta 3$ integrin shRNA (Figure 6B). CD90induced phosphorylation of mTOR and AMPK were attenuated after the inhibition of $\beta 3$ integrin (Figure 6C). Anchorage-independent growth was decreased in a similar fashion (Figure 6D). Anti- $\beta 3$ integrin antibody effectively decreased the anchorage-independent growth induced by CD90 (Figure 6D). Co-incubation of tumor cells with lentiviral particles containing $\beta 3$ integrin shRNA dramatically inhibited the tumor formation in mice (Figure 6E). In a therapeutic model, the lentiviral particles were delivered at 24 days after tumor implantation. Lentiviral expression of $\beta 3$ integrinshRNA inhibited tumor growth (Supplementary Figure S6A). These data indicate that CD90 activates mTOR and AMPK to promote anchorage-independent growth via binding to $\beta 3$ integrin.

\section{DISCUSSION}

In this report, we demonstrate that the expression of the cancer stem cell marker CD90 enhances the tumorigenicity of liver cancer cells via the induction of CD133. Microenvironment carcinogenic stimuli, including 


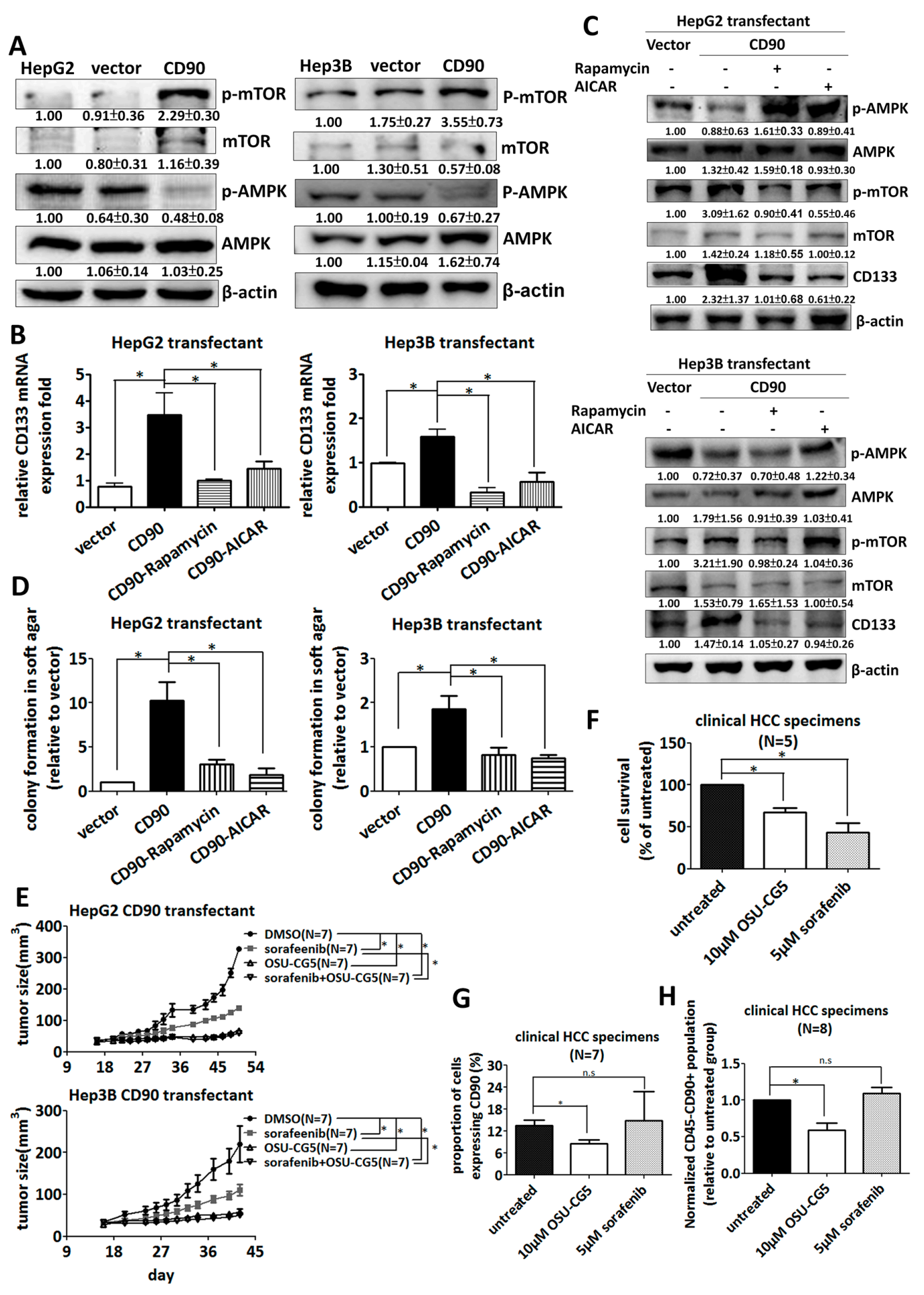

Figure 5: Inhibition of the AMPK/mTOR pathway attenuates the upregulation of CD133 by CD90 in cell lines and fresh liver cancer specimen. A. The phosphorylation of mTOR and AMPK in the transfectants was determined by western blotting. The quantitative data represent mean $\pm \mathrm{SD}(n=3)$. CD133 mRNA B. and protein expression $\mathbf{C}$. in the transfectants were determined by quantitative RT-PCR and western blotting respectively after rapamycin or AICAR treatment for 24 hours. D. The transfectants were plated in soft agar and treated with the indicated inhibitors. Colonies were monitored for 14 days and quantified using Image-Pro Plus software. Data represent mean $\pm \operatorname{SEM}(n=3)$. E. The CD90 transfectant was subcutaneously injected to NOD/SCID mice. The mice were intraperitoneally injected with indicated sorafenib or OSU-CG5 after 14 days and the drug was administrated to mice every other day. $P$ value was calculated using two-way anova analysis and $*$ indicated $P<0.0001 . \mathbf{F}, \mathbf{G}$. and $\mathbf{H}$. The liver cancer cells from the freshly isolated HCC specimens were incubated with OSU-CG5 or sorafenib for 24 hours. The cell numbers were counted in (F), and the CD90 expression was determined by flow cytometry in (G) The population of CD45-CD90+ cancer stem cell-like was determined by flow cytometry in $(\mathrm{H})$ Data represent mean \pm SEM. $P$ value was calculated using one-way anova analysis and $*$ indicated $P<0.01$. 

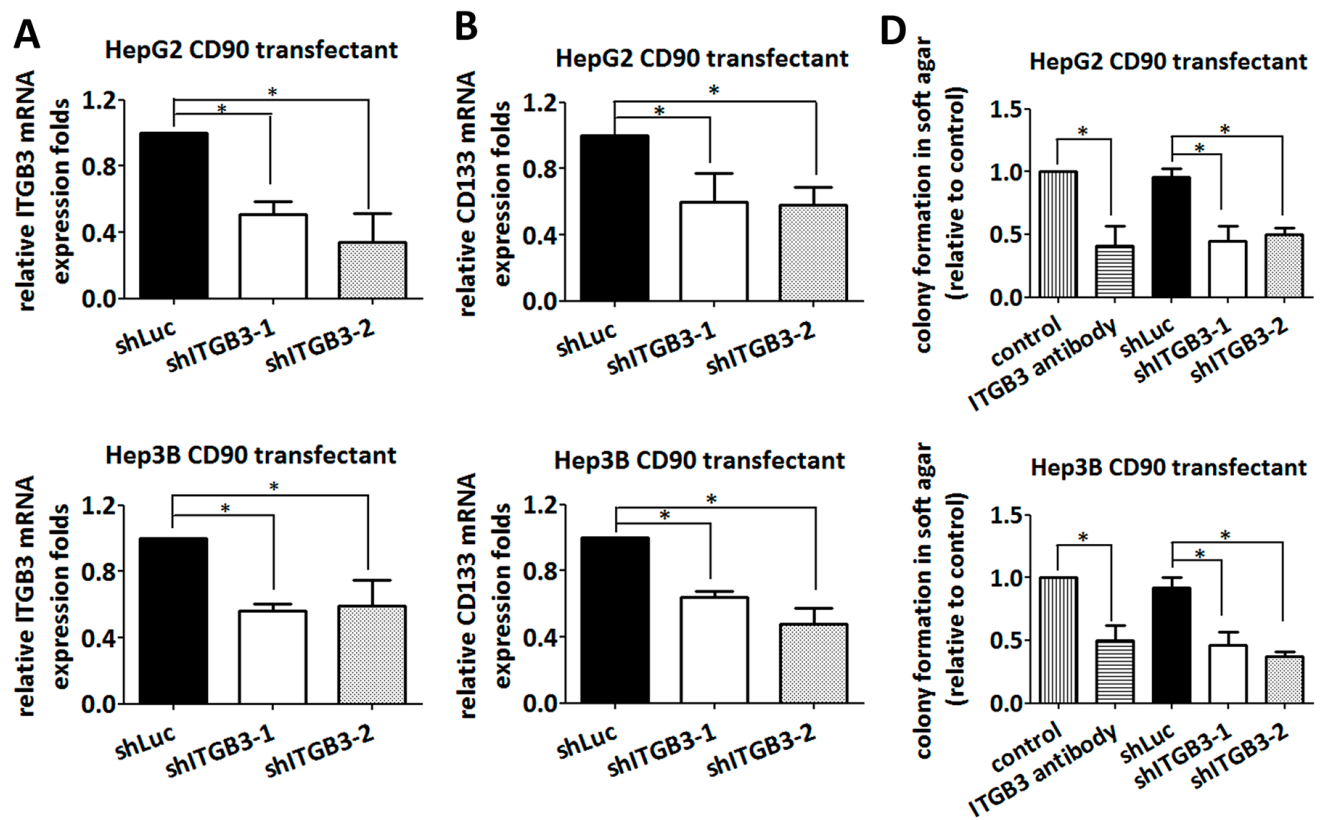

C HepG2 CD90 transfectant
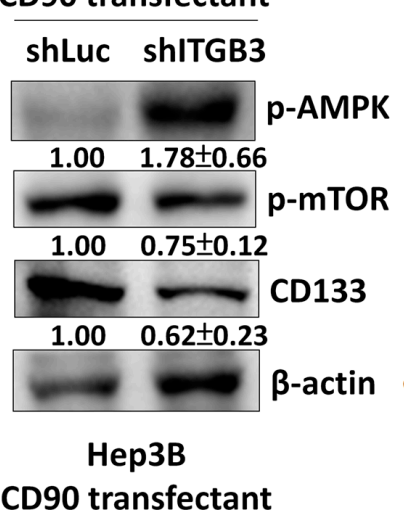

shLuc shITGB3

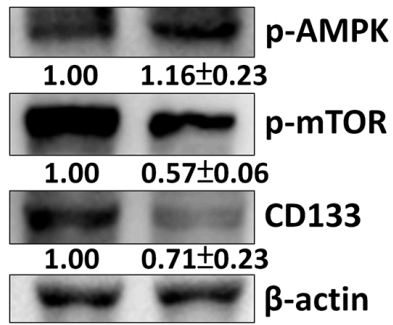

$\mathbf{E}$
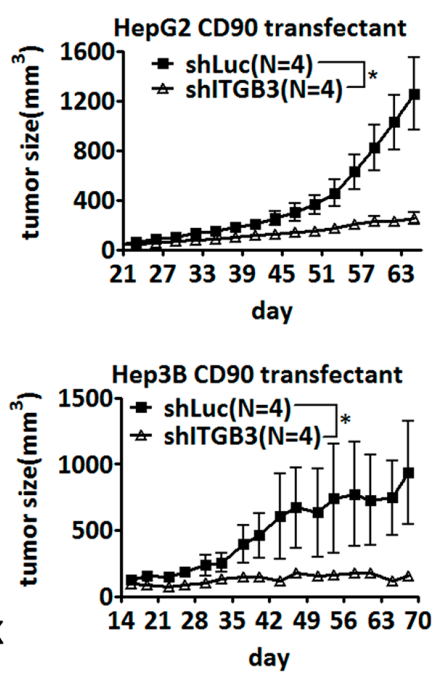

$\mathbf{F}$

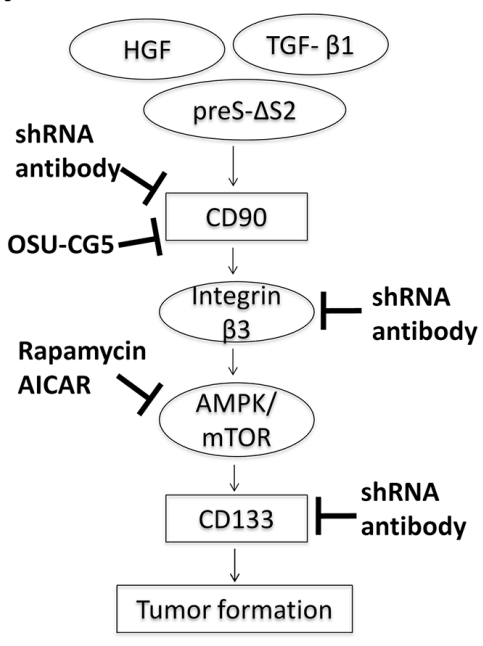

Figure 6: Silencing of $\beta 3$ integrin inhibits tumor formation and CD133 expression induced by CD90. A. $\beta 3$ Integrin mRNA was downregulated in CD90 transfectants with lentiviral particles containing shRNA targeting $\beta 3$ integrin or luciferase. The mRNA was determined by quantitative RT-PCR. Data represent mean $\pm \operatorname{SEM}(n=3)$. B. CD133 mRNA expression in the cells expressing $\beta 3$ integrin or luciferase shRNA was determined by quantitative RT-PCR. Data represent mean $\pm \operatorname{SEM}(n=5)$. C. The phosphorylation of mTOR and AMPK and the expression of CD133 were determined by western blotting. Data represent mean $\pm \mathrm{SD}(n=3)$. D. Anchorage-independent growth of HepG2 or Hep3B CD90 transfectant was determined using soft agar assay after lentiviral infection of the indicated shRNA or $\beta 3$ integrin antibody treatment Data represent mean $\pm \operatorname{SEM}(n=5) . P$ value was calculated using one-way anova analysis and $*$ indicated $P<0.05$. E. CD 90 transfectants were co-injected with lentiviral particles containing luciferase or $\beta 3$ integrin shRNA into NOD/SCID mice. The tumor growth was monitored twice a week. Data represent mean $\pm \operatorname{SEM}(n=4) . P$ value was calculated using two-way anova analysis and * indicated $P<0.05$. F. A model is presented to illustrate the signal axis of CD90 and CD133. CD90 binds to $\beta 3$ integrin and increases the expression of CD133 and tumor growth. The AMPK/mTOR pathway is essential for the induction of CD133. The indicated shRNAs, antibodies and inhibitors suppress the growth of tumor cells in vitro and in vivo. 
HGF, TGF- $\beta-1$, and mutant HBV large surface protein, induce the expression of CD90 and CD133. The expression of CD133 is higher in CD90-positive cells than that in CD90-negative fresh tumor cells. Signaling analyses reveal that $\mathrm{AMPK} / \mathrm{mTOR}$ and $\beta 3$ integrin are required for the induction of CD133 by CD90. Importantly, the tumorigenicity of cancer cells can be blocked by shRNA or antibody targeting CD90, $\beta 3$ integrin, and CD133. Finally, energy restriction mimetic agent OSU-CG5 effectively decreases the cells expressing CD90 and tumor growth. A scheme of signal axis of CD90 and CD133 and therapeutic opportunities is illustrated in Figure 6F. In accordance to our results, sorafenib is unable to induce apoptotic response on CD44+ cells in liver cancer [43]. This report suggests that therapy targeting signal axis of CD90 and CD133 may be combined with current therapy, such as sorafenib, in treating liver cancer.

Hepatic cancer stem cells have been identified by several markers [44, 45], including EpCAM, CD90, CD133, CD44, CD24, and CD13. CD133 is co-expressed with many other markers that are used to define liver cancer stem cells [23, 46]; thus, it is logical to hypothesize that there is a correlation between these markers. Our results demonstrated that ectopic expression of CD90 induced the expression of liver cancer stem cell markers, including CD133, CD24, and EpCAM. Our result provided the first evidence that expression of these stem cell markers are influenced by each other, which will be important for us to study the difference and lineage of cancer stem cells. For example, CD90 mainly induced the expression of CD133 and CD24, but had little effect on the expression of CD13. The correlation between these cancer stem cell markers provides a novel strategy to treat cancer. In this report, inhibitors targeting CD90-integrinAMPK/mTOR-CD133 are effective in attenuating tumor progression. A recent study also indicates that CD24 contributes to the urothelial tumorigenesis and metastasis [47]. Therefore, targeting these cancer stem cell markers may be a general strategy for cancer treatment. CD90positive cancer stem cell population is reported to have a characteristic of pro-glycolysis gene expression signature [48]. We have examined the therapeutic molecule OSUCG5 which mainly targets glucose transporter and decreases energy sensing pathway. Sorafenib is better than OSU-CG5 in inhibiting cell growth. However, OSUCG5 selectively decreased the CD90-positive cells which are potentially represented as cancer initiating cells. Therefore, combination of OSU-CG5 and sorafenib may provide a novel therapy for liver cancer.

Ectopic expression of mutant RLE CD90 did not affect mTOR phosphorylation, CD133 expression, and anchorage-independent growth. These results suggest that the binding of CD90 to integrin in cis is required for enhancing tumor formation. The cis binding of CD90 to integrin was also observed in the previous study describing the correlation between CD90 and $\alpha v \beta 5$ integrin in myofibroblast. A binding of $\alpha v \beta 5$ integrin to CD90 in cis competes the binding to latent TGF- $\beta-1$ complex, thereby inhibiting the contraction-iduced latent TGF- $\beta-1$ activation on myofibroblast differentiation and lung fibrosis [41]. On the other hand, CD90 binds to $\alpha \mathrm{v} \beta 3$ integrin in trans by syndecan- 4 and leads to focal adhesion formation in melanoma invasion [49]. The tyrosine phosphorylation and focal adhesion formation in astrocyte are induced by thymoma expressing CD90 [50]. CD90 expressed on endothelium functions as a ligand for $\alpha v \beta 3$ integrin expressed on melanoma and the interaction between $\alpha v \beta 3$ integrin and CD90 in trans is correlated with the metastasis [27]. Furthermore, CD90 represents a counter receptor for leukocyte integrin Mac-1 and has the ability to bind the monocyte and PMNC (polymorphonuclear cell) [51]. In this report, a cis-interaction between CD90 and $\beta 3$ integrin is required for anchorage-independent growth (Supplementary Figure S4). It will be important to study whether there is a trans-interaction between CD90 on liver cancer cell and the molecules on neighboring cells in hepatocellular carcinogenesis.

CD133 is expressed in many cancers, such as liver cancer, colon cancer, and brain gliomas [13, 14, 19]. Previous studies have also supported the notion that CD133 plays an oncogenic role in cancer. Overexpression of CD133 induces tumorigenicity in HEK293 cells [52], and CD133 is a potential oncogene in head and neck cancer [53]. The downregulation of CD133 by an HDAC6 inhibitor inhibits cancer cell differentiation [54]. Therefore, targeting CD133 and its related signaling pathways may be a feasible strategy for treating cancer.

In summary, our report indicates that the CD90integrin-AMPK/mTOR-CD133 signal axis is required for hepatocarcinogenesis. We further provide evidences to support a new therapeutic approach by inhibiting the signal axis pathway between cancer stem cell markers.

\section{MATERIALS AND METHODS}

\section{Reagents, chemicals and antibodies}

Hepatocyte growth factor (HGF) and transforming growth factor $\beta 1$ (TGF- $\beta$-1) were purchased from Pepro Tech (Rocky Hill, USA). Rapamycin and AICAR were purchased from Calbiochem (San Diego, CA, USA). The anti-CD90 conjugated $\mathrm{PE}$ antibody was purchased from eBioscience (San Diego, CA, USA). The anti-EpCAM antibody was purchased from Santa Cruz Biotechnology (Santa Cruz, CA, USA). The anti-mTOR and anti-CD90 antibodies were purchased from Epitomics (Burlingame, CA, USA). The anti-CD133 and anti-CD44 antibodies were purchased from Abcam (Cambridge, UK). The anti-phospho-mTOR, anti-phosphor-AMPK, anti-AMPK, anti-mTOR, secondary horse anti-mouse horseradish peroxidase-conjugated and anti-rabbit horseradish peroxidase-conjugated antibodies were purchased from Cell Signaling (Beverly, MA, USA). 
The anti- $\beta$-actin antibody was purchased from Chemicon (Pittsburgh, PA, USA). The AC133 antibody was purchased from Miltenyi Biotec (Bergisch Gladbach, Germany).

\section{Cell lines}

Hep3B, HepG2 and HuH7 cell lines were obtained from Dr. I.J. Su and Dr. T.M. Lin and authenticated by DNA (STR) profiling at Genelabs Life Science in Oct 2014 and Jan 2013, respectively. PLC/PFR/5 cell line was provided by B.C. Yang.

\section{Anchorage-independent growth ability}

The protocol is modified from a previous report [36]. $1.5 \mathrm{ml}$ of $0.6 \%$ agar in DMEM containing $10 \%$ FBS were prepared as underlayer in plastic petri dish. Five thousand cells to be tested were suspended in $1 \mathrm{ml}$ of $0.3 \%$ agar in DMEM supplemented with 10\% FBS and poured over the underlayer. The plates were placed in a $5 \% \mathrm{CO}_{2}$ and $37^{\circ} \mathrm{C}$ atmosphere humidified incubator. The colonies were stained with $0.05 \%$ crystal violet after 14 days and photographed. The colonies were quantified using the Image-pro Plus software.

\section{Tumorigenicity in NOD/SCID mice}

Male NOD/SCID mice were obtained from the Animal Center of the National Cheng Kung University (Tainan, Taiwan). The mouse experiments were approved by the Animal Welfare Committee at National Cheng Kung University. Five million HepG2, HuH7, HepG2 stable transfectants, or $\mathrm{HuH} 7$ stable transfectants were suspended in $200 \mu \mathrm{l}$ of DMEM and implanted subcutaneously into the NOD/SCID mice. Ten million Hep3B and Hep3B stable transfectants were implanted into the NOD/SCID mice. To investigate the antitumor effects of sorafenib and OSU-CG5, sorafenib and OSUCG5 were administered intraperitoneally with $10 \mathrm{mg} / \mathrm{kg}$ sorafenib or $50 \mathrm{mg} / \mathrm{kg}$ OSU-CG5 every other day after tumor implanted for 14 days.

\section{Flow cytometry}

The trypsinized cells were labeled with antiCD90-PerCp-Cy5.5, anti-CD133-PE, anti-CD45-APC, and anti-CD90-PE, respectively. After incubating with primary antibody, the cells were washed with phosphate buffered saline (PBS) and then resuspended in PBS supplemented with $1 \%$ FBS and $1 \mathrm{mM}$ EDTA. The cells were analyzed using a FACS Calibur (BD. Biosciences, San Jose, CA, USA).

\section{Western blotting analysis}

Cell lysate was prepared in RIPA lysis buffer. The protein concentration was determined with Micro BCA ${ }^{\mathrm{TM}}$ protein assay kit (Millipore, MA, USA). $35 \mu \mathrm{g}$ protein was loaded into acrylamide gels and then transferred onto polyvinylidene fluoride membranes (Amersham Biosciences, Piscataway, NJ) after electrophoresis. The membranes were incubated with horseradish peroxidaseconjugated secondary antibody and probed with ECL western blotting detection system (Millipore, MA, USA) and visualized with the BioSpectrum AC imaging system.

\section{Sphere formation assay}

Five thousand HepG2 and Hep3B stable transfectants were plated in the ultra-low attachment culture dishes (Corning Incorporated, Corning, NY, USA) in DMEM supplemented with $50 \mathrm{ng} / \mathrm{ml} \mathrm{HGF}$ and $50 \mathrm{ng} /$ $\mathrm{ml}$ EGF. The cells were incubated at $37^{\circ} \mathrm{C}, 5 \% \mathrm{CO}_{2}$ for 14 days and then counted under light microscope.

\section{Quantitative real-time reverse transcription-PCR}

Total RNA was extracted with TRIzol (MDBio, Taiwan). The cDNA was synthesized using M-MLV transcriptase (Promega, MI, USA). The quantitative PCR was performed using KAPA ${ }^{\mathrm{TM}}$ PROBE FAST qPCR Kit (KAPABIOSYSTEMS, Boston, Massachusetts, USA) on an Applied Biosystems StepOnePlus ${ }^{\mathrm{TM}}$ RealTime PCR Systems. The CD44 and integrin $\beta 3$ mRNA expression were analyzed using Maxima SYBR Green qPCR Master Mix kit (Fermentas, Canada). The CD90 primers were 5'-aggacgagggcacctacac-3' (sense) and $5^{\prime}$-gccetcacacttgaccagtt-3' (antisense); the CD133 primers were $5^{\prime}$-aaggcatatgaatccaaaattga- $3^{\prime}$ (sense) and $5^{\prime}$-ccaccagag gcatcagaataa-3' (antisense); the CD13 primers were 5'-ca tccatcagagatggcagac-3' (sense) and $5^{\prime}$-tgctgaagagatcgtt ctgg- $3^{\prime}$ (antisense); the CD24 primers were $5^{\prime}$-atgggcagagcaa tggtg-3' (sense) and 5'-tggaataaatctgcgtgggta-3' (antisense); the EpCAM primers were $5^{\prime}$-agttggtgcacaaaatactgtcat- $3^{\prime}$ (sense) and $5^{\prime}$-ctcccaagttttgagccatt-3' (antisense); the HPRT primers were $5^{\prime}$-tgatagatccattcctatgactgtaga- $3^{\prime}$ (sense) and 5'-caagacattctttccagttaaagttg-3' (antisense); the CD44 primers were $5^{\prime}$-tttgcattgcagtcaacagtc-3' (sense) and $5^{\prime}$-gttacaccccaatcttcatgtccac-3' (antisense) and the $\beta 3$ integrin primers were $5^{\prime}$-ccgtgacgagattgagtca- $3^{\prime}$ (sense) and 5'-aggatggactttccactagaa-3' (antisense).

\section{RNA interference and lentivirus production}

The shRNA targeting CD90, CD133, $\alpha \mathrm{V}$ integrin, $\beta 1$ integrin, $\beta 5$ integrin and $\beta 3$ integrin were obtained from National RNAi Core facility (Academia Sinica, Taipei, Taiwan). The shRNA used for silencing gene expression are following: TRCN0000057024, TRCN0000057025, TRCN0000062145, TRCN0000062146, TRCN0000010 768, TRCN0000010769, TRCN0000026945, TRCN00001 22920, TRCN0000057743, TRCN0000057744, TRCN 0000003236 and TRCN0000003237. The lentivirus 
production was managed according to the protocol provided from the National RNAi Core facility. For in vivo model with lentiviral shRNA, the CD90 transfectants and the lentiviral particles containing shRNA were co-injected subcutaneously into NOD/SCID mice. For therapeutic model with lentiviral shRNA, the HepG2 CD90 transfectants were implanted subcutaneously into NOD/SCID mice and the lentiviral particles containing luciferase or integrin $\beta 3$ shRNA were delivered intratumorally at 24 days after transfectants implantation.

\section{Tissue samples}

The tumor specimens were obtained from the National Cheng Kung University Hospital (Tainan, Taiwan) with the approval of the Institutional Review Board, and the tumor and non-tumor tissues were diagnosed by a pathologist. The specimens of hepatocellular carcinoma were obtained from Human Biobank within the Research Center of Clinical Medicine of the National Cheng Kung University Hospital (Tainan, Taiwan) with the approval of the Institutional Review Board (NCKUH IRB number: ER-97-148 and ER-101-245).

\section{Generation of CD90 RLE mutant cDNA}

The RLD sequence of CD90 was mutated into RLE sequence with QuikChange ${ }^{\mathrm{TM}}$ site-directed mutagenesis kit (Stratagene, La Jolla, CA, USA) according to the manufacturer's instructions.

\section{Statistical analysis}

All statistical analyses were performed using GraphPad Prism version 4 (GraphPad Software, La Jolla, CA, USA). The analysis was performed using unpaired $t$-test, one-way anova analysis and two-way anova analysis, respectively.

\section{ACKNOWLEDGMENTS AND FUNDING}

This work was supported in part by grant number NSC 97-2320-B-006-003-MY3 to Dr. Ming-Derg Lai from the Ministry of Science and Technology, Taiwan, Republic of China, and in part by the Innovative and Exploratory Project grant number B035 from National Cheng Kung University. This work was also supported by grant NHRI-EX100-9927B1 from the National Health Research Institute, Taiwan, and the grant to Establish Centers of Excellence for Cancer Research in Taiwan, number DOH101-TD-C-111-003, from the Department of Health, Executive Yuan, Taiwan.

\section{CONFLICTS OF INTEREST}

None Declared.

\section{REFERENCES}

1. Abou-Shady $M$, Baer $H U$, Friess $H$, Berberat $P$, Zimmermann A, Graber H, Gold LI, Korc M, Buchler MW. Transforming growth factor betas and their signaling receptors in human hepatocellular carcinoma. Am J Surg. 1999; 177:209-215.

2. Shiota G, Okano JI, Kawasaki H, Kawamoto T, Nakamura T. Serum Hepatocyte Growth-Factor Levels in Liver-DiseasesClinical Implications. Hepatology. 1995; 21:106-112.

3. Karabulut S, Tas F, Akyuz F, Ormeci AC, Serilmez M, Soydinc HO, Vatansever S, Yasasever V. Clinical significance of serum hepatocyte growth factor (HGF) levels in hepatocellular carcinoma. Tumour Biol. 2014; 35:2327-2333.

4. Wang HC, Huang WY, Lai MD, Su IJ. Hepatitis B virus pre-S mutants, endoplasmic reticulum stress and hepatocarcinogenesis. Cancer Sci. 2006; 97:683-688.

5. Wang HC, Chang WT, Chang WW, Wu HC, Huang W, Lei HY, Lai MD, Fausto N, Su IJ. Hepatitis B virus pre-S2 mutant upregulates cyclin A expression and induces nodular proliferation of hepatocytes. Hepatology. 2005; 41:761-770.

6. Cho KR, Vogelstein B. Suppressor gene alterations in the colorectal adenoma-carcinoma sequence. J Cell Biochem Suppl. 1992; 16G:137-141.

7. Reya T, Morrison SJ, Clarke MF, Weissman IL. Stem cells, cancer, and cancer stem cells. Nature. 2001; 414:105-111.

8. Bonnet D, Dick JE. Human acute myeloid leukemia is organized as a hierarchy that originates from a primitive hematopoietic cell. Nat Med. 1997; 3:730-737.

9. Schatton T, Frank NY, Frank MH. Identification and targeting of cancer stem cells. Bioessays. 2009; 31:1038-1049.

10. Oliveira LR, Jeffrey SS, Ribeiro-Silva A. Stem cells in human breast cancer. Histol Histopathol. 2010; 25:371-385.

11. Chiba T, Kita K, Zheng YW, Yokosuka O, Saisho H, Iwama A, Nakauchi H, Taniguchi H. Side population purified from hepatocellular carcinoma cells harbors cancer stem cell-like properties. Hepatology. 2006; 44:240-251.

12. Chiba T, Kamiya A, Yokosuka O, Iwama A. Cancer stem cells in hepatocellular carcinoma: Recent progress and perspective. Cancer Lett. 2009; 286:145-153.

13. Singh SK, Hawkins C, Clarke ID, Squire JA, Bayani J, Hide T, Henkelman RM, Cusimano MD, Dirks PB. Identification of human brain tumour initiating cells. Nature. 2004; 432:396-401.

14. O'Brien CA, Pollett A, Gallinger S, Dick JE. A human colon cancer cell capable of initiating tumour growth in immunodeficient mice. Nature. 2007; 445:106-110.

15. Rountree CB, Ding W, He L, Stiles B. Expansion of CD133Expressing Liver Cancer Stem Cells in Liver-Specific Phosphatase and Tensin Homolog Deleted on Chromosome 10-Deleted Mice. Stem Cells. 2009; 27:290-299.

16. Yao J, Zhang T, Ren J, Yu M, Wu G. Effect of CD133/ prominin-1 antisense oligodeoxynucleotide on in vitro growth characteristics of Huh-7 human hepatocarcinoma 
cells and U251 human glioma cells. Oncol Rep. 2009; 22:781-787.

17. Song W, Li H, Tao K, Li R, Song Z, Zhao Q, Zhang F, Dou K. Expression and clinical significance of the stem cell marker CD133 in hepatocellular carcinoma. Int J Clin Pract. 2008; 62:1212-1218.

18. Yin S, Li J, Hu C, Chen X, Yao M, Yan M, Jiang G, Ge C, Xie H, Wan D, Yang S, Zheng S, Gu J. CD133 positive hepatocellular carcinoma cells possess high capacity for tumorigenicity. Int J Cancer. 2007; 120:1444-1450.

19. Ma S, Chan KW, Hu L, Lee TK, Wo JY, Ng IO, Zheng BJ, Guan XY. Identification and characterization of tumorigenic liver cancer stem/progenitor cells. Gastroenterology. 2007; 132:2542-2556.

20. You H, Ding W, Rountree CB. Epigenetic regulation of cancer stem cell marker CD133 by transforming growth factor-beta. Hepatology. 2010; 51:1635-1644.

21. Yang W, Yan HX, Chen L, Liu Q, He YQ, Yu LX, Zhang SH, Huang DD, Tang L, Kong XN, Chen C, Liu SQ, Wu MC, Wang HY. Wnt/beta-catenin signaling contributes to activation of normal and tumorigenic liver progenitor cells. Cancer Res. 2008; 68:4287-4295.

22. Yamashita T, Ji J, Budhu A, Forgues M, Yang W, Wang HY, Jia H, Ye Q, Qin LX, Wauthier E, Reid LM, Minato H, Honda M, Kaneko S, Tang ZY, Wang XW. EpCAM-positive hepatocellular carcinoma cells are tumor-initiating cells with stem/progenitor cell features. Gastroenterology. 2009; 136:1012-1024.

23. Zhu Z, Hao X, Yan M, Yao M, Ge C, Gu J, Li J. Cancer stem/progenitor cells are highly enriched in CD133+CD44+ population in hepatocellular carcinoma. Int J Cancer. 2010; 126:2067-2078.

24. Yang ZF, Ho DW, Ng MN, Lau CK, Yu WC, Ngai P, Chu PW, Lam CT, Poon RT, Fan ST. Significance of CD90+ cancer stem cells in human liver cancer. Cancer Cell. 2008; 13:153-166.

25. Cohen PY, Breuer R, Wallach-Dayan SB. Thy1 up-regulates FasL expression in lung myofibroblasts via Src family kinases. Am J Respir Cell Mol Biol. 2009; 40:231-238.

26. Lung HL, Bangarusamy DK, Xie D, Cheung AK, Cheng Y, Kumaran MK, Miller L, Liu ET, Guan XY, Sham JS, Fang Y, Li L, Wang N, Protopopov AI, Zabarovsky ER, Tsao SW, et al. THY1 is a candidate tumour suppressor gene with decreased expression in metastatic nasopharyngeal carcinoma. Oncogene. 2005; 24:6525-6532.

27. Saalbach A, Wetzel A, Haustein UF, Sticherling M, Simon JC, Anderegg U. Interaction of human Thy-1 (CD 90) with the integrin alphavbeta3 (CD51/CD61): an important mechanism mediating melanoma cell adhesion to activated endothelium. Oncogene. 2005; 24:4710-4720.

28. Hermosilla T, Munoz D, Herrera-Molina R, Valdivia A, Munoz N, Nham SU, Schneider P, Burridge K, Quest AF, Leyton L. Direct Thy-1/alphaVbeta3 integrin interaction mediates neuron to astrocyte communication. Biochim Biophys Acta. 2008; 1783:1111-1120.

29. Avalos AM, Labra CV, Quest AF, Leyton L. Signaling triggered by Thy-1 interaction with beta 3 integrin on astrocytes is an essential step towards unraveling neuronal Thy-1 function. Biol Res. 2002; 35:231-238.

30. Yamashita T, Honda M, Nakamoto Y, Baba M, Nio K, Hara Y, Zeng SS, Hayashi T, Kondo M, Takatori H, Mizukoshi E, Ikeda H, Zen Y, Takamura H, Wang XW, Kaneko S. Discrete nature of EpCAM+ and CD90+ cancer stem cells in human hepatocellular carcinoma. Hepatology. 2013; 57:1484-1497.

31. Llovet JM, Bruix J. Molecular targeted therapies in hepatocellular carcinoma. Hepatology. 2008; 48:1312-1327.

32. Rybak AP, Bristow RG, Kapoor A. Prostate cancer stem cells: deciphering the origins and pathways involved in prostate tumorigenesis and aggression. Oncotarget. 2015; 6:1900-1919.

33. Yamada T, Abei M, Danjoh I, Shirota R, Yamashita T, Hyodo I, Nakamura Y. Identification of a unique hepatocellular carcinoma line, Li-7, with CD13(+) cancer stem cells hierarchy and population change upon its differentiation during culture and effects of sorafenib. BMC cancer. 2015; 15:260.

34. Gedaly R, Galuppo R, Musgrave Y, Angulo P, Hundley J, Shah M, Daily MF, Chen C, Cohen DA, Spear BT, Evers BM. PKI-587 and sorafenib alone and in combination on inhibition of liver cancer stem cell proliferation. J Surg Res. 2013; 185:225-230.

35. Su YJ, Lai HM, Chang YW, Chen GY, Lee JL. Direct reprogramming of stem cell properties in colon cancer cells by CD44. EMBO J. 2011; 30:3186-3199.

36. Huang HL, Hsu HP, Shieh SC, Chang YS, Chen WC, Cho CY, Teng CF, Su IJ, Hung WC, Lai MD. Attenuation of argininosuccinate lyase inhibits cancer growth via cyclin A2 and nitric oxide. Mol Cancer Ther. 2013; 12:2505-2516.

37. Sunayama J, Matsuda K, Sato A, Tachibana K, Suzuki K, Narita Y, Shibui S, Sakurada K, Kayama T, Tomiyama A, Kitanaka C. Crosstalk between the PI3K/mTOR and MEK/ ERK pathways involved in the maintenance of self-renewal and tumorigenicity of glioblastoma stem-like cells. Stem Cells. 2010; 28:1930-1939.

38. Arafa el SA, Abdelazeem AH, Arab HH, Omar HA. OSU-CG5, a novel energy restriction mimetic agent, targets human colorectal cancer cells in vitro. Acta Pharmacol Sin. 2014; 35:394-400.

39. Berman-Booty LD, Chu PC, Thomas-Ahner JM, Bolon B, Wang D, Yang T, Clinton SK, Kulp SK, Chen CS. Suppression of prostate epithelial proliferation and intraprostatic progrowth signaling in transgenic mice by a new energy restriction-mimetic agent. Cancer Prev Res (Phila). 2013; 6:232-241.

40. Wilhelm S, Carter C, Lynch M, Lowinger T, Dumas J, Smith RA, Schwartz B, Simantov R, Kelley S. Discovery 
and development of sorafenib: a multikinase inhibitor for treating cancer. Nat Rev Drug Discov. 2006; 5:835-844.

41. Zhou Y, Hagood JS, Lu B, Merryman WD, MurphyUllrich JE. Thy-1-integrin alphav beta5 interactions inhibit lung fibroblast contraction-induced latent transforming growth factor-beta1 activation and myofibroblast differentiation. J Biol Chem. 2010; 285:22382-22393.

42. Itami S, Tamotsu S, Sakai A, Yasuda K. The roles of THY1 and integrin beta 3 in cell adhesion during theca cell layer formation and the effect of follicle-stimulating hormone on THY1 and integrin beta3 localization in mouse ovarian follicles. Biol Reprod. 2011; 84:986-995.

43. Fernando J, Malfettone A, Cepeda EB, Vilarrasa-Blasi R, Bertran E, Raimondi G, Fabra A, Alvarez-Barrientos A, Fernandez-Salguero P, Fernandez-Rodriguez CM, Giannelli G, Sancho P, Fabregat I. A mesenchymal-like phenotype and expression of CD44 predict lack of apoptotic response to sorafenib in liver tumor cells. Int J Cancer. 2015; 136:E161-72.

44. Ji J, Wang XW. Clinical implications of cancer stem cell biology in hepatocellular carcinoma. Semin Oncol. 2012; 39:461-472.

45. Yamashita T, Honda M, Nakamoto Y, Baba M, Nio K, Hara Y, Zeng SS, Kondo TH, Takatori H, Mizukoshi E, Ikeda H, Zen Y, Takamura H, Wang XW, Kaneko S. Discrete nature of $\operatorname{EpCAM}(+)$ and $\mathrm{CD} 90(+)$ cancer stem cells in human hepatocellular carcinoma. Hepatology. 2013; 57:1484-97.

46. Shmelkov SV, Butler JM, Hooper AT, Hormigo A, Kushner J, Milde T, St Clair R, Baljevic M, White I, Jin DK, Chadburn A, Murphy AJ, Valenzuela DM, Gale NW, Thurston G, Yancopoulos GD, et al. CD133 expression is not restricted to stem cells, and both CD133+ and CD133- metastatic colon cancer cells initiate tumors. J Clin Invest. 2008; 118:2111-2120.

47. Overdevest JB, Knubel KH, Duex JE, Thomas S, Nitz MD, Harding MA, Smith SC, Frierson HF, Conaway M, Theodorescu D. CD24 expression is important in male urothelial tumorigenesis and metastasis in mice and is androgen regulated. Proc Natl Acad Sci U S A. 2012; 109:3588-96.

48. Mei L, Choi KM, Walsh M, Jin M, Guzman Grace. Immunolevel of hepatocyte cancer stem cell marker CD90 correlates with glycolytic enzyme Hkii, oxidative stress and tumor grade in hepatocellular carcinoma. Gastroenterology. 2014; 146:S-953.

49. Avalos AM, Valdivia AD, Munoz N, Herrera-Molina R, Tapia JC, Lavandero S, Chiong M, Burridge K, Schneider P, Quest AF, Leyton L. Neuronal Thy-1 induces astrocyte adhesion by engaging syndecan-4 in a cooperative interaction with alphavbeta3 integrin that activates PKCalpha and RhoA. J Cell Sci. 2009; 122:3462-3471.

50. Leyton L, Schneider P, Labra CV, Ruegg C, Hetz CA, Quest AF, Bron C. Thy-1 binds to integrin beta(3) on astrocytes and triggers formation of focal contact sites. Curr Biol. 2001; 11:1028-1038.

51. Wetzel A, Chavakis T, Preissner KT, Sticherling M, Haustein UF, Anderegg U, Saalbach A. Human Thy-1 (CD90) on activated endothelial cells is a counterreceptor for the leukocyte integrin Mac-1 (CD11b/CD18). J Immunol. 2004; 172:3850-3859.

52. Canis M, Lechner A, Mack B, Zengel P, Laubender RP, Koehler U, Heissmeyer V, Gires O. CD133 induces tumourinitiating properties in HEK293 cells. Tumour Biol. 2013; 34:437-443.

53. Chen YS, Wu MJ, Huang CY, Lin SC, Chuang TH, Yu CC, Lo JF. CD133/Src axis mediates tumor initiating property and epithelial-mesenchymal transition of head and neck cancer. PloS one. 2011; 6:e28053.

54. Mak AB, Nixon AM, Kittanakom S, Stewart JM, Chen GI, Curak J, Gingras AC, Mazitschek R, Neel BG, Stagljar I, Moffat J. Regulation of CD133 by HDAC6 Promotes betaCatenin Signaling to Suppress Cancer Cell Differentiation. Cell Rep. 2012; 2:951-963. 